\title{
Differences in the Functioning and Occupational Activity in People with Mental Disorders: A Gender Perspective
}

\author{
Lina Díaz-Castro*1, Héctor Cabello-Rangel ${ }^{2}$ and Mariana Chávez-Cervantes ${ }^{3}$ \\ ${ }^{1}$ Direction of Epidemiological and Psychosocial Research, México \\ ${ }^{2}$ Division of Diagnostic Aid, Mexico
}

${ }^{3}$ Medical Director of the Carmen's Psychiatric Hospital, Mexico

*Corresponding author: Lina Díaz-Castro, Direction of Epidemiological and Psychosocial Research, Ramón de la Fuente Muñiz National Psychiatry Institute, Calzada México-Xochimilco 101 col, San Lorenzo Huipulco, C.P. 14370, Mexico City, Mexico

\section{ARTICLE INFO}

Received: 梆 November 20, 2019

Published: 蔧December 02, 2019

Citation: Lina Díaz-Castro, Héctor Cabello-Rangel, Mariana Chávez-Cervantes. Differences in the Functioning and Occupational Activity in People with Mental Disorders: A Gender Perspective. Biomed J Sci \& Tech Res 23(2)-2019. BJSTR. MS.ID.003886.

Keywords: Mental Disorders; Schizophrenia; Disability; WHODAS 2.0; Occupational Activity

Abbreviations: MD: Mental Disorders; DALYs: Disability-Adjusted Life Years; YLDs: Years Lived with Disability; CIF: Classification of Functionality,

\section{ABSTRACT}

Introduction: The disability caused by the mental disorders (MD) limit the individual and social functioning. This study examines the relationships between functioning domains with gender, diagnosis and occupational activity in people with MD.

Methods: A cross-sectional study was conducted during 2017. Patients of a psychiatric hospital answered the questionnaires

1) Sociodemographic and clinical variables, and

2) WHODAS, assesses domains of functioning (Do):

a. Cognition,

b. Mobility,

c. Self-care,

d. Getting along,

e. Life activities, and

f. Participation. Analysis $\mathrm{x}^{2}$, t-test, ANOVA and Tamhane were performed.

Results: 302 patients with average age 33 years were surveyed, 48.7\% were unemployment. The women showed less disability than men (participation: 47.50 vs 62.47; $\mathrm{t}=-3.274, \mathrm{p}=.001$; cognition: 35.83 vs $54.28 \mathrm{t}=-3.608, \mathrm{p}=.000$ ). ANOVA for diagnosis: size large effect in Do4: $\mathrm{F}(6,178)=4.56, \mathrm{p}=<.000$; and occupational activity: size large in Do1 F $(5,179)=9.08, p=<.000 ; \operatorname{Do} 4 F(5,179)=8.64, p=<.000$. Tamhane: student and housewife increase the functionality 52.66 and 51.52 compared to be unemployment.

Conclusion: All the domains of functioning are affected in the MD but being men, having psychosis and unemployment increasing disability.

\section{Introduction}

In Mexico during 2017 mental disorders (MD) represented 1,424.94 of Disability-Adjusted Life Years (DALYs) per 100,000 inhabitants, ranking 8th in the global burden of disease in the general population and in all age groups, they also occupy the first place with 18.98\% of Years Lived with Disability (YLDs) according to the Institute for Health Metrics and Evaluation [1]. The most 
prevalent MD in Mexico are depression (4.66\%), anxiety (3.09\%), substance use (2.28\%), alcohol use (1.77\%), bipolar disorders (1.72\%) and schizophrenia (1.39\%). The MD involve suffering and functional deterioration so they cannot only be understood as the presence of psychopathological signs and symptoms, it should also be considered the degree of disability associated with them [2]. The high levels of disability caused by the MD limit the individual and social functioning of the patient, such as having a job [3]. The disability associated with MD leads to negative economic consequences derived from direct costs for the care of the disease and indirect cost such as those associated with loss of productivity of the patient and primary caregiver [4].

Which places these patients in a situation of social inequality due to high unemployment rates; in fact, one study estimated the economic decline due to schizophrenia at 2.7 billion euros, of which $50.5 \%$ are due to indirect costs such as the loss of productivity of the affected person, loss of productivity of caregivers and compensation for disability; and $49.5 \%$ due to direct costs [5] Another study associated the loss of productivity with the continuity of treatment in anxious and depressed patients [6]. Therefore, the disability associated with mental disorders is a challenge that lies in understanding the relationship of the psychopathology of mental disorder and disability to be able to identify and intervening in early stages of the disorders in order to improve the prognosis and the economic consequences [7]. In this perspective, this study examines the relationships between the specific domains of daily functioning through the World Health Organization-Disability Assessment Schedule (WHODAS 2.0) with gender, diagnosis, and occupational activity in people with mental disorders.

\section{Methods}

Study design. A cross-sectional study was carried out using the survey technique. The study was approved by the Ethics and Research Committee of the Fray Bernardino Alvarez Psychiatric Hospital (HPFBA initials of Hospital Psiquiátrico "Fray Bernardino Álvarez"), and was carried out during the second semester of 2017; the research followed the principles of the Declaration of Helsinki and all the participants signed an informed consent.

\section{Sample}

The participants were selected from the HPFBA, who met the following selection criteria:

1) Men and women over 18 years of age who received medical attention for a MD at the institution during the study time;

2) Have the presence of a responsible relative, legal representative or primary caregiver;

3) Agree to answer the survey and sign the informed consent.

\section{Instruments}

Questionnaire 1 "Users of Services", which is an ad hoc questionnaire that contains the section on sociodemographic and clinical variables of the participants; the occupational activity variable was constructed from the demographic information section that was obtained when carrying out the surveys of WHODAS 2.0 itself, since it investigates what the participant is engaged in and if he receives remuneration for that activity, and not only if he has a generic employment. Questionnaire 2 "WHODAS 2.0", to evaluate the level of functioning and disability, which is a multidimensional scale of the International Classification of Functionality, Disability and Health (CIF), which groups the different domains of a person in a determined state of health, where the concept of functioning is considered as a global term that refers to all bodily functions, activities and participation, and in turn, evaluates the level of disability, encompassing the deficiencies, limitations in the activity, or restrictions in participation [8].

The WHODAS 2.0 is a validated instrument worldwide with good psychometric properties, the test-retest reliability analysis showed an intraclass correlation coefficient of 0.69-0.89 at the question level; from 0.93-0.96 at the domain level; and of 0.98 at a general level; as well as high internal consistency with a Cronbach coefficient of 0.98 [9] through the exploration of the degree of difficulty experienced in the following domains: domain 1 (Do1): cognition, understanding and communication; domain 2 (Do2): mobility, movement and displacement (getting around); domain 3 (Do3): self-care, hygiene, dressing, eating and remaining alone; domain 4 (Do4): getting along, interactions with other people; domain 5 (Do5): activities of life, with two modalities: domain 5 1 (Do5 1) domestic responsibilities, and domain 52 (Do5 2) work and/or school responsibilities; and Do6: participation in society, getting involved in community activities [8]. In the present study, the version of 36 questions administered by the interviewer was used, since it allows evaluating both the levels of functionality and disability in general, and specifics for each domain. Most of the questions are developed in the Likert format, where an ascending scale is exposed, which usually ranges from the first option "None" to the fifth "Extreme or cannot do it", according to the level of difficulty that the interviewee reports to perform different activities.

\section{Statistic Analysis}

Derived from the frequency distribution of the variables and measures of central tendency and variability measures were applied (mean deviation, standard deviation); bivariate analysis for association considering all the variables and indicators included in the mentioned instruments such as sex, diagnosis and occupational activity. To obtain performance and disability scores through WHODAS 2.0, the simple form lists the response options from 1 to 5 (being "None" = 1, and "Extreme or can not do it" = 5) and add up the points according to what the participant answers: the higher 
the grade, the greater the disability; in the complex score, the answers are weighted according to the different questions and levels of severity, from which the qualifications of each option are recoded; subsequently the sum of the points obtained globally and by domain is made. This process is carried out electronically, through the application of an algorithm developed by the WHO for the statistical analysis program SPSS, where a score between 0 (without disability) and 100 (total disability) is generated; for our analysis we used the complex method $[10,11]$. For the categorization of the WHODAS 2.0 score, the CIF methodology was resumed in the following way: 0 - 4\% no disability, 5 - 24\% mild, 25 - 49\% moderate, 50 - 95\% serious and $95-100 \%$ complete [12]. We applied t test to know the differences of means in the domains of functioning by sex and the one-way analysis of variance (ANOVA) to know the differences of means in the domains of functioning by diagnosis and by variables of occupational activity. In all cases statistical significance tests of the values obtained were carried out. All analyzes were done with the support of the statistical software SPSS version 25 .

\section{Results}

The sample consisted of $\mathrm{n}=302$ patients with an average age of 33.4 years $(S D=11.75$ ) of which $62.9 \%$ were men, with an average 9.6 years of schooling ( $\mathrm{SD}=3.98)$. In relation to marital status only $14.6 \%$ were married. Regarding the place of origin, the patients were mostly residents of Mexico City (55.6\%), and the state of Mexico (37.1\%). For the diagnostic classification it was first obtained through the ICD-10 [13], once obtained, they were grouped according to the first digit obtaining the following diagnostic groups: schizophrenia 48\% ( $\mathrm{n}=145)$, other psychotic disorders 19.9\% ( $\mathrm{n}=60)$, personality disorders $8.9 \%(\mathrm{n}=27)$, bipolar disorder 8.6\% $(n=26)$, depressive disorders $8.3 \%(n=25)$, non-specific mental disorder 3.3\% $(\mathrm{n}=10)$ and anxiety disorder $3 \%(n=9)$. Regarding of the occupational activity the majority of participants did not have a job and this due to health problems with
$48.7 \%(n=147)$ of which $22.4 \%$ were women ( $n=33)$; or they had a self-employment with $16.2 \%(n=49)$ of them $38.8 \%$ corresponded to women; $12.9 \%$ ( $n=39$ ) of them $38.5 \%$ of women they did not have employment for reasons other than having health problems; 8.6\% mentioned dedicating themselves to household activities as an occupational activity $(n=26$, of which $96.2 \%$ corresponded to women); $7 \%$ ( $n=21$, of which $42.9 \%$ corresponded to women) had formal employment, and the remaining 6.6\% ( $n=20$, where $55 \%$ corresponded to women) were classified as students. In the bivariate analysis there were differences in relation to gender and marital status ( $=15.56, \mathrm{p}=.000$ ); between gender and occupation ( $=55.51 ; \mathrm{p}=.000)$; and between the gender and the diagnosis $(=$ $37.49, \mathrm{p}=.000)$.

Regarding to the levels of disability and functioning, the Figure 1 shows the averages in each of the functioning domains. The domain corresponding to the participation in society ( Do6) and the domain of interpersonal getting along (Do4) showed values between 50 to $95 \%$, that is severe disability; the domain of the cognitive functioning (Do1) and the domain of life activities in its two modalities: household (Do5 1) and work (Do5 2) are found with values between 25 to $49 \%$, that is, moderate disability. These values of disability are reflected in the global measurement of the scale for the whole sample (st_32 = 41\%), which the global disability is considered moderate. To set the behavior of the different domains of functioning by gender, we performed a t test, in which we can observe that there is a difference in the means of disability, according to the measurement of the WHODAS 2.0. In domain of cognition women present a moderate disability, while men show in that same domain a serious disability, the same happens exactly with the domain of interpersonal relationships (Do4), the domain of life activities at household, and in domain of participation in society; only in domain of mobility women show greater affectation than men although this association was not significant (Table 1).

Table 1: Global levels of disability in the different domains of the World Health Organization Disability Assessment Schedule 2.0 (WHODAS 2.0) by gender.

\begin{tabular}{|c|c|c|c|c|c|}
\hline Domains & Men (means) & Women (means) & Statistical (t) & Standard Error & p-value \\
\hline Do1 & 54.28 & 35.83 & -3.608 & 5.112 & 0 \\
\hline Do2 & 12.45 & 17.29 & 1.365 & 3.547 & 0.174 \\
\hline Do3 & 8.48 & 9.83 & 0.446 & 3.034 & 0.656 \\
\hline Do4 & 57.13 & 42.92 & -2.677 & 5.311 & 0.008 \\
\hline Do51 & 55.52 & 38.33 & -3.177 & 5.41 & 0.002 \\
\hline Do52 & 39.51 & 21.43 & -2.369 & 7.632 & 0.022 \\
\hline Do6 & 62.47 & 47.5 & -3.274 & 4.571 & 0.001 \\
\hline St_s32 & 44.67 & 34.02 & -2.904 & 3.667 & 0.004 \\
\hline St_s36 & 33.23 & 24.79 & -1.481 & 5.698 & 0.145 \\
\hline
\end{tabular}

Note: *Statistically significant values. Do1 = Cognition Do2 = Mobility: getting around Do3 = Self-care Do4=Getting along Do5

= Life activities: Do51 $=$ Household, Do5 $2=$ Work or school Do6 $=$ Participation in society St_32= Global WHODAS 2.0 St $\_36$

= Global WHODAS 2-0 including work. 


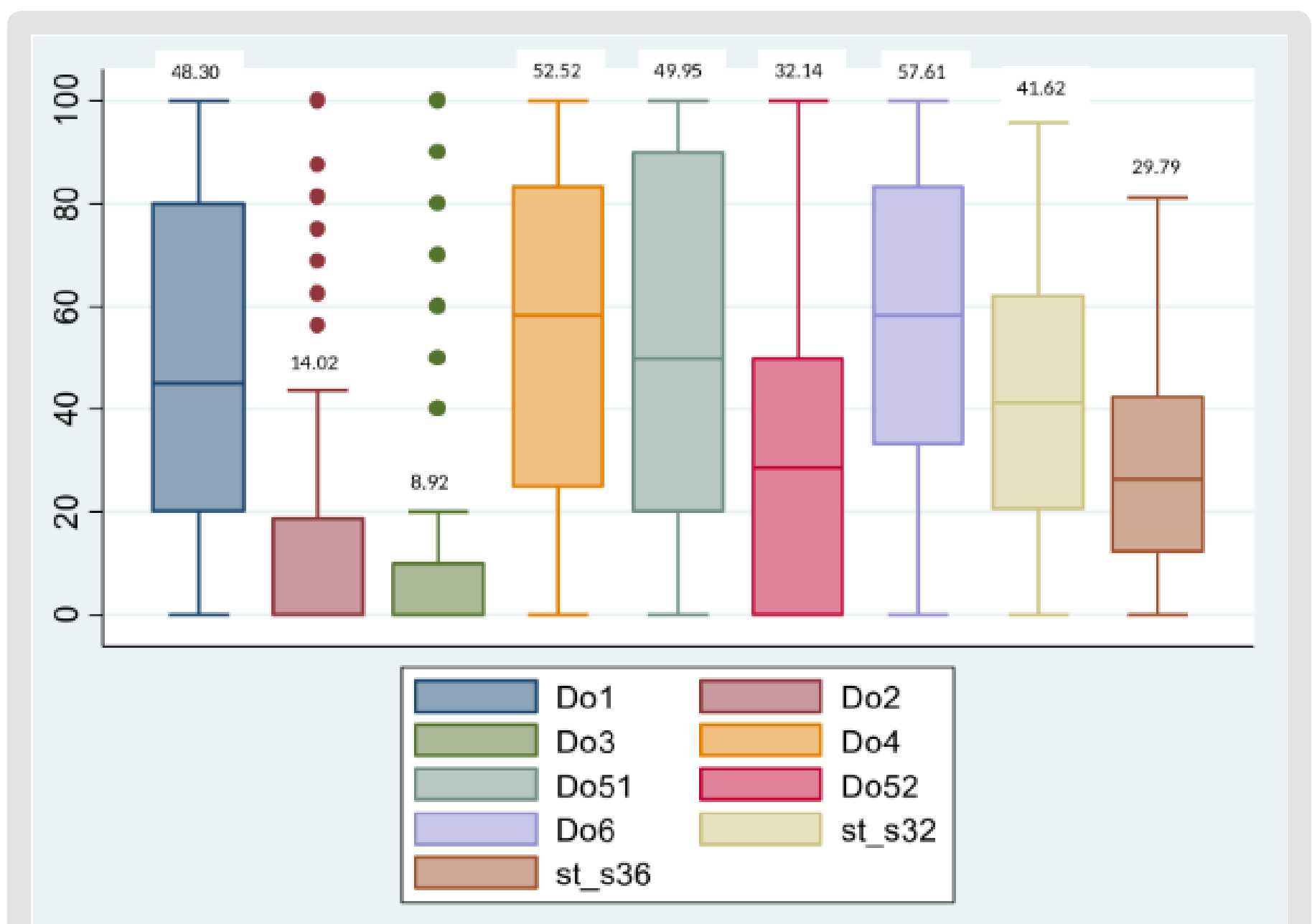

Figure 1: Disability profile in mental disorders by the World Health Organization Disability Assessment Schedule (WHODAS 2.0).

Note: Do1= Cognition Do2=Mobility Do3= Self-Care Do4= Getting Along D05= Life activities Do5 1= Household, Do5 2= Work or school D06= Participation in society St_32= Global WHODAS 2.0 St_36= Global WHODAS 2.0 including work.

The following results of the one-way ANOVA between groups indicates that there are statistically significant differences between the groups of the functioning domains of WHODAS 2.0 and the average scores by type of diagnosis, with an average effect size in Do1: $\mathrm{F}$ $(6,178)=2.89, p=<.010 ;$ Do3: $F(6,178)=2.81, p=<.012 ;$ Do4: $F$ $(6,178)=4.56, p=<.000 ; \operatorname{Do5} 1: F(6,178)=3.94, p=<.001 ;$ Do6: $\mathrm{F}(6,178)=3.63, \mathrm{p}=<.002$; and st_s32: $\mathrm{F}(6,178)=3.72, \mathrm{p}=<.002$. Therefore the Tamhane multiple means comparison test was performed which reported that all the groups of functional domains indicated in the ANOVA test are significant, differing according to the type of diagnosis; the lowest functioning in the diagnosis of schizophrenia was observed when compared with the diagnosis of anxiety disorders ( $\mathrm{p}=.011)$; and vice versa, the greater functioning in the diagnosis of anxiety disorders as compared to the diagnosis "schizophrenia" ( $p=.011$ ) (Table 2). Regarding occupational activity, the results of the one-way ANOVA between groups indicates that there are statistically significant differences between the groups of the functioning domains of WHODAS 2.0 and the average scores by type of occupational activity, with a large effect size in Do1: $F$ $(5,179)=9.08, \mathrm{p}=<.000 ;$ Do3: $F(5,179)=3.44, \mathrm{p}=<.005 ;$ Do4: $\mathrm{F}(5,179)=8.64, \mathrm{p}=<.000 ; \operatorname{Do5} 1: \mathrm{F}(5,179)=7.69, \mathrm{p}=<.000$; Do6: $F(5,179)=8.87, p=<.000$; and st_s32: $F(5,179)=8.61, p=$ $<.000$. Finally, the analysis of difference of means by Tamhane test, indicates that all the groups of domains of functioning differ among themselves according to the occupational activity; observing the greater functioning in activity as "student" when compared with the occupational activity " unemployment for health condition" or "unemployment due to health reasons" ( $\mathrm{p}=.002)$; and the lower 
performance in the activity "self-employment", as compared to the activity "unemployment for health condition" (p =.000) (Table 3).

Table 2: Tamhane: mean difference between diagnostic groups for each functioning domain.

\begin{tabular}{|c|c|c|c|c|c|c|c|}
\hline \multirow[t]{2}{*}{ Domain } & \multirow[t]{2}{*}{ (I) Diagnostic } & \multirow[t]{2}{*}{ (J) Diagnostic } & \multirow[t]{2}{*}{ Mean Difference } & \multirow[t]{2}{*}{ Standard Error } & \multirow[t]{2}{*}{ Sig. } & \multicolumn{2}{|c|}{$95 \% \mathrm{CI}$} \\
\hline & & & & & & Lower & Upper \\
\hline \multirow[t]{4}{*}{ Do1 } & Anxiety disorders & Schizophrenia & $-27.96^{*}$ & 6.55 & 0.022 & -52.94 & -2.98 \\
\hline & & Other psychotic disorders & $-34.17^{*}$ & 9.19 & 0.017 & -64.63 & -3.72 \\
\hline & Schizophrenia & Anxiety disorders & $27.96^{*}$ & 6.56 & 0.022 & 2.98 & 52.94 \\
\hline & Other psychotic disorders & Anxiety disorders & $34.17^{*}$ & 9.19 & 0.017 & 3.72 & 64.6 \\
\hline \multirow[t]{4}{*}{ Do3 } & Anxiety disorders & Schizophrenia & $-10.98^{*}$ & 1.84 & 0.000 & -16.7 & -5.25 \\
\hline & Bipolar disorder & Schizophrenia & $-10.35^{*}$ & 1.94 & 0.000 & -16.38 & -4.33 \\
\hline & Schizophrenia & Anxiety disorders & $10.98^{*}$ & 1.84 & 0.000 & 5.25 & 16.7 \\
\hline & & Bipolar disorder & $10.35^{*}$ & 1.94 & 0.000 & 4.33 & 16.38 \\
\hline \multirow[t]{2}{*}{ Do4 } & Anxiety disorders & Schizophrenia & $-40.76^{*}$ & 8.92 & 0.027 & -77.64 & -3.88 \\
\hline & Schizophrenia & Anxiety disorders & $40.76^{*}$ & 8.92 & 0.027 & 3.88 & 77.64 \\
\hline \multirow[t]{2}{*}{ Do51 } & Anxiety disorders & Schizophrenia & $-42.83^{*}$ & 8.44 & 0.011 & -77.19 & -8.47 \\
\hline & Schizophrenia & Anxiety disorders & $42.83^{*}$ & 8.44 & 0.011 & 8.47 & 77.19 \\
\hline \multirow[t]{2}{*}{ Do6 } & Anxiety disorders & other psychotic disorders & $-35.94^{*}$ & 9.64 & 0.044 & -71.27 & -0.6 \\
\hline & Non-specific mental disorder & Anxiety disorders & $35.94^{*}$ & 9.64 & 0.044 & 0.6 & 71.27 \\
\hline \multirow[t]{2}{*}{ St_s32 } & Anxiety disorders & Schizophrenia & $-24.9^{9 *}$ & 5.72 & 0.031 & -48.18 & -1.8 \\
\hline & Schizophrenia & Anxiety disorders & $24.99^{*}$ & 5.72 & 0.031 & 1.8 & 48.18 \\
\hline
\end{tabular}

Note: *Statistically significant values. *Negative values indicate a decrease in the functioning, while positive values indicate an increase in functioning.

Do1 $=$ Cognition Do2 = Mobility: getting around Do3 $=$ Self-care Do4 = Getting along Do5 = Life activities: Do5 $1=$ Household, Do5 2 = Work or school Do6 = Participation in society St_32 = Global WHODAS 2.0.

Table 3: Tamhane: mean difference between occupational activity groups for each functioning domain.

\begin{tabular}{|c|c|c|c|c|c|c|c|}
\hline \multirow[t]{2}{*}{ Domain } & \multirow[t]{2}{*}{ (I) Occupation } & \multirow[t]{2}{*}{ (J) Occupation } & \multirow[t]{2}{*}{ Mean Difference } & \multirow[t]{2}{*}{ Standard Error } & \multirow[t]{2}{*}{ Sig. } & \multicolumn{2}{|c|}{$95 \% \mathrm{CI}$} \\
\hline & & & & & & Lower & Upper \\
\hline \multirow{5}{*}{ Do1 } & Unemployment for other reasons & $\begin{array}{l}\text { Unemployment for } \\
\text { health condition }\end{array}$ & $31.00^{*}$ & 7.52 & 0.003 & 7.43 & 54.57 \\
\hline & & Housewife & $51.53^{*}$ & 8.62 & 0.000 & 24.76 & 78.29 \\
\hline & & Self-employment & $43.32^{*}$ & 8.87 & 0.000 & 16 & 70.64 \\
\hline & & Student & $52.67^{*}$ & 11.51 & 0.002 & 15.08 & 90.26 \\
\hline & & Formal employment & $37.79 *$ & 10.82 & 0.023 & 3.27 & 72.3 \\
\hline \multirow{3}{*}{ Do3 } & $\begin{array}{l}\text { Unemployment for health condi- } \\
\text { tion }\end{array}$ & Self-employment & $12.82^{*}$ & 2.58 & 0.000 & 5.1 & 20.55 \\
\hline & & Student & $13.42^{*}$ & 2.57 & 0.000 & 5.7 & 21.14 \\
\hline & & Formal employment & $14.25^{*}$ & 2.43 & 0.000 & 6.92 & 21.58 \\
\hline \multirow{3}{*}{ Do4 } & Unemployment for other reasons & Housewife & $36.84^{*}$ & 10.03 & 0.01 & 5.68 & 68 \\
\hline & & Self-employment & $43.75^{*}$ & 9.19 & 0.000 & 15.42 & 72.08 \\
\hline & $\begin{array}{l}\text { Unemployment for health condi- } \\
\text { tion }\end{array}$ & Self-employment & $29.67^{*}$ & 6.57 & 0.001 & 9.31 & 50.03 \\
\hline \multirow{5}{*}{ Do51 } & Unemployment for & Housewife & $41.10^{*}$ & 10.01 & 0.003 & 10.03 & 72.16 \\
\hline & other reasons & Self-employment & $38.91^{*}$ & 9.38 & 0.002 & 9.95 & 67.88 \\
\hline & & Formal employment & $42.49^{*}$ & 11.86 & 0.018 & 4.7 & 80.27 \\
\hline & Unemployment for & Housewife & $25.60^{*}$ & 7.4 & 0.026 & 1.92 & 49.27 \\
\hline & health condition & Self-employment & $23.42^{*}$ & 6.52 & 0.012 & 3.33 & 43.5 \\
\hline
\end{tabular}




\begin{tabular}{|c|c|c|c|c|c|c|c|}
\hline \multirow{5}{*}{ Do6 } & Unemployment for & $\begin{array}{l}\text { Unemployment for } \\
\text { health condition }\end{array}$ & $20.62^{*}$ & 5.76 & 0.013 & 2.74 & 38.5 \\
\hline & other reasons & Housewife & $42.81^{*}$ & 6.97 & 0.000 & 21.15 & 64.47 \\
\hline & & Self-employment & $38.90^{*}$ & 7.48 & 0.000 & 15.93 & 61.87 \\
\hline & & Student & $42.57^{*}$ & 10.33 & 0.01 & 7.74 & 77.4 \\
\hline & $\begin{array}{l}\text { Unemployment for health condi- } \\
\text { tion }\end{array}$ & Housewife & $22.18^{*}$ & 5.69 & 0.007 & 4.2 & 40.17 \\
\hline \multirow{5}{*}{ St_s32 } & Unemployment for other reasons & Housewife & $29.27 *$ & 6.2 & 0.000 & 10.01 & 48.53 \\
\hline & & Self-employment & $30.15^{*}$ & 5.64 & 0.000 & 12.76 & 47.54 \\
\hline & & Student & $33.58^{*}$ & 8.03 & 0.006 & 7.05 & 60.11 \\
\hline & & Formal employment & $26.15^{*}$ & 7.43 & 0.023 & 2.26 & 50.04 \\
\hline & $\begin{array}{l}\text { Unemployment for health condi- } \\
\text { tion }\end{array}$ & Self-employment & $16.62^{*}$ & 4.28 & 0.004 & 3.54 & 29.71 \\
\hline
\end{tabular}

Note: *Statistically significant values. Do1 = Cognition Do2 = Mobility: getting around Do3 = Self-care Do4=Getting along Do5 = Life activities: Do5 $1=$ Household, Do5 2 = Work or school Do6 = Participation in society St_32=Global WHODAS 2.0.

\section{Discussion}

The results of our study are relevant in the sense that it reports the degree of affectation of the different domains of functioning in people with different mental disorders, in the understanding that disability is the main predictor of the needs of health care and services, however, it is not commonly evaluated [14]; such is the case that there are no defined standards or thresholds [15]. Although all functioning domains are affected in this population, the degree of differentiated involvement by domains is very notable, we find levels of severe disability (values of more than $50 \%$ disability), in the domains of participation in society and interpersonal getting along (relationship), which have a logic with the way of presentation and evolution of mental disorders, especially in those considered serious as schizophrenia and other primary psychotic disorders [16], in which we observe a decrease in social functioning much earlier than symptomatic appearance, mainly the one that demands social interaction. We also found moderate disability (those domains with disability levels between 25 and 49\%), in the domain of cognition and activities at home; regarding these observed data, we know that mental disorders are the cause of various cognitive dysfunctions (abilities to pay attention, remember, process information, solve problems, organize and reorganize information, communicate and react to received information) and are often the primary symptom in psychotic disorders [17], for example in the schizophrenia the executive functions components have been associated with the general measure of functional outcome, by the way, studies have suggested that cognitive task performance can be broken down into the same broad domains in both schizophrenic and other populations (like healthy population) [18].

Respect to life activities which is divided into two, on the one hand activities at home and on the other hand activities at work or school, higher disability score was observed in activities of the home, most of the patients in our study do not have a job, nor do they study, therefore the perception of functioning is not dependent on the area in which they are located. Another relevant finding of our study is that these levels of disability are different by gender; women had lower average levels of disability in the domains of participation in society, household activities and interpersonal getting along, which are placed in moderate disability, compared to men who have a serious disability in those same domains. In domain 5 for those who study or work (Do5 2), both the average in women and men is placed in moderate disability, but women have a lower average disability, as in the rest of the areas of functioning except for the domain of mobility, in which both genders have a level of disability that corresponds to mild, but women have a higher average than men.

Despite the fact that this difference in the mobility disability is significant in the understanding that women have higher prevalence than men in painful symptoms without medical explanation that cause disability or are associated with affective or anxious mental disorders [19]. The fact of finding these differences in the levels of disability between men and women, forced us to carry out an exhaustive analysis according to the mental pathology and the main work activity that they reported. When comparing the differences in disability between the different mental disorders, the average disability in the groups of schizophrenia and other primary psychotic disorders is enormous compared to the anxiety disorders which are considered common mental disorders, although they are the most prevalent in the population, it was not so in our study sample; we could observe that the most prevalent diagnosis was schizophrenia with almost $50 \%$, a condition that was observed more in men (with prevalence greater than 70\%).

Having schizophrenia and other psychotic disorders leads to disability in almost all domains of functioning, as has been reported in other studies $[20,21]$. We observe great differences especially in the domains of cognition, participation in society, and above all and at a higher score the domain of life activities such as household, and this difference in functioning is only observed in a significant way at a global level (st_32), but only in the sample of those who do not study or work, like most of the people in this study, in other 
words, when people with mental disorders perform activities that keep them busy productively, such as a job, these differences in their functioning are not observed globally (st_36), as reported in another study, unemployment is not only caused by having a mental disorder, but not having a job can also generate a mental disorder [22]. Due to the above-mentioned, the results of disability and type of occupational activity found were of great interest, it was observed that people with mental disorders that have being students or being housewives work as an occupational activity much better than those who are unemployed for reasons other than being ill, that is to say, despite the fact that people carry out activities that are not remunerated, such as dedicating themselves to household activities (housewives), being active in academic or home activities favors their global functioning.

An interesting fact was the fact that people who do not have a job for health reasons, have better performance than a person without employment for any other reason, this may be because having a health condition deserves to spend time either for your attention or for recovery, but does not necessarily imply that this situation will be permanent. Having any occupational activity is as relevant in all people regardless of their health condition, as if that health condition alludes to the presence of a mental disorder. Because of all the above, it is recommended that in medical practice, the diagnosis and evaluation of disability be made, more in psychiatry, in the understanding of the criterion of clinically significant impairment that contemplates the definition of mental disorders [15] and every time that disability is sensitive to therapeutic change [21] that is, it improves symptomatology and should improve functioning, although in the assessment of disability related to mental disorders there are no established thresholds to interpret specific and global scores, hence the importance of this study, which showed that there is a relationship between gender and levels of functioning, differentiated by the type of diagnosis and, above all, by the type of occupational activity.

It would be necessary to carry out validation studies and confirmatory analysis of the domains of functionality of the WHODAS 2.0 in the population with mental disorders, but differentiated by age groups and time of evolution of the mental disorder, before and after the treatment, this in order to establish points of cutting (standards and thresholds) and designing specific intervention strategies that turn towards favoring the domains of global functioning of people with mental disorders differentiated by gender Work integration can be difficult for people with a psychiatric disability such as schizophrenia, bipolar and depressive disorders, even though the majority of people with a psychiatric condition can and would like to work [23]. However, systematic research is needed to understand the individual and organizational factor that can affect the work productivity is stable across time [23]. In other hand, to increase awareness of the meaning and characteristics of strategies can inform a person-oriented approach in rehabilitation, the knowledge can be used in clinical encounters to reflect together with the patient, exploring present options and introducing modifications to their particular work and life context [24].

Self-managed work functioning in common mental disorders involves diverse strategies interpreted as sustainable over time, seem to be reflective in the sense that the worker consciously applies and adapts these strategies [24]. In conclusion, in people with mental disorders the level of functioning is seriously affected in the domains of cognition, participation in society and especially in everyday activities (chores at home), which is associated with high rates of unemployment and economic burden further exacerbates the prognosis. Men suffer higher levels of disability in general, but women show greater affectation of the mobility domain, which forces to jointly evaluate not only the symptoms of mental pathology, but the degree of disability that entails, in order to offer interventions multidisciplinary focused on the needs of the person and with a gender approach, which impact on improving the health condition of the affected population.

\section{Acknowledgment}

The authors thank the psychiatrists Janet Olivera García, Pablo Vera Flores, Miguel Angel Herrera Estrella and Sofía Berenice Vázquez for their time spent collecting and filling out the questionnaires in the HPFBA.

\section{Source of Financing}

This research has not received specific grants from public sector agencies, commercial sector or non-profit entities.

\section{References}

1. (2018) Institute for Health Metrics and Evaluation. GBD Compare Data Visualization [base de datos en internet]. Seattle WA, University of Washington, USA.

2. Robles R, Medina R, Paez F, Becerra B (2010) Evaluación de funcionalidad, discapacidad y salud para la rehabilitacion psicosocial de paciente asilados por trastornos mentales graves. Salud Ment 33(1): 67-75.

3. Banerjee S, Chatterji P, Lahiri K (2017) Effects of psychiatric disorders on labor market outcomes: a latent variable approach using multiple clinical indicators. Heal Econ 26(2): 184-205.

4. Shaughnessy TM, Parker FR, Hollenshead JH, Clottey EN, Rubin H (2017) Contemporary Data and Trends in the Economic Costs of Mental Disabilities. Behav Sci Law 35(1): 162-177.

5. Marcellusi A, Fabiano G, Viti R, Francesa Morel PC, Nicolò G, et al. (2018) Economic burden of schizophrenia in Italy: A probabilistic cost of illness analysis. BMJ Open 8(2): 1-8

6. Chiavegatto Filho ADP, Wang YP, Campino ACC, Malik AM, Viana MC, et al. (2015) Incremental health expenditure and lost days of normal activity for individuals with mental disorders: results from the São Paulo Megacity Study. BMC Public Health 15(1): 1-9.

7. Fowler D, French P, Banerjee R, Barton G, Berry C, et al. (2017) Prevention and treatment of long-term social disability amongst young people with emerging severe mental illness with social recovery therapy (The PRODIGY Trial): Study protocol for a randomised controlled trial. Trials 18(1): 315 .

8. Vazquez Barquero JL, Vazquez BE, Herrera CS, Saiz J, Uriarte M, et al. (2000) [Spanish version of the new World Health Organization Disability Assessment Schedule II (WHO-DAS-II): initial phase of development and pilot study. Cantabria disability work group]. Actas Esp Psiquiatr 28(2): 77-87. 
9. Üstün T, Chatterji S, Bickenbach J, Kostanjsek N, Schneider M (2003) The International Classification of Functioning, Disability and Health: a new tool for understanding disability and health. Disabil Rehabil 25(11-12): 565-571.

10. (2015) Organización Mundial de la Salud. Medición de la Salud y la Discapacidad (1 ${ }^{a}$ Edn.). Ginebra: Organización Mundial de la Salud.

11. Üstün TB, Chatterji S, Kostanjsek N, Rehm J, Kennedy C, et al. (2010) Developing the World Health Organization Disability Assessment Schedule 2.0. Bull World Health Organ 88(11): 815-823.

12. (2001) Organizacion Mundial de la Salud. Clasificación Internacional del Funcionamiento, de la Discapacidad y de la Salud: CIF (1 ${ }^{\text {a }}$ Edn). Ginebra: Organización Mundial de la Salud.

13. (2000) World Health Organization. Guía de bolsillo de la clasificación CIE-10: clasificación de los trastornos mentales y del comportamiento. Madrid: Editorial Médica Panamericana.

14. Martínez Taboas A, Medina Sustache E, González Díaz DY, Prats Aparicio AC, Garrahan Viejo AM, et al. (2017) El WHODAS 2.0 en Puerto Rico: Psicometría y su relación con la escala de evaluación de actividad global con pacientes psiquiátricos. Salud Soc 8(1): 82-93.

15. Konecky B, Meyer EC, Marx BP, Kimbrel NA, Morissette SB (2014) Using the WHODAS 2.0 to assess functional disability associated with DSM5 mental disorders. Am J Psychiatry 171(8): 818-819.

16. Folsom D, Hawthorne W, Lindamer L, Gilmer T, Bailey A, et al. (2005) Prevalence and risk factors for homelessness and utilization of mental health services. Am J Psychiatry 162(2): 370-376.

17. Quijano M, Aponte HM, Salazar Uricoechea C (2014) Cambios cognoscitivos en la enfermedad mental de pacientes que asisten al

ISSN: 2574-1241

DOI: 10.26717/BJSTR.2019.23.003886

Lina Díaz-Castro. Biomed J Sci \& Tech Res

(C) This work is licensed under Creative Commons Attribution 4.0 License

Submission Link: https://biomedres.us/submit-manuscript.php
Programa de Hospital Día del Hospital Psiquiátrico Universitario del Valle. Diversitas 4(1): 113-121.

18. Berberian AA, Gadelha A, Dias NM, Mecca TP, Comfort WE, et al. (2019) Componen mechanisms of executive function in schizophrenia and their contribution to functional outcomes. Braz J Psychiatry 41(1): 22-30.

19. (2018) Organización Panamericana de la Salud. La carga de los trastornos mentales en la Región de las Américas (1aㅡ Edn). Washington, D.C.: Organización Panamericana de la Salud.

20. Buist Bouwman MA, De Graaf R, Vollebergh WAM, Alonso J, Bruffaerts R, et al. (2006) Functional disability of mental disorders and comparison with physical disorders: A study among the general population of six European countries. Acta Psychiatr Scand 113(6): 492-500.

21. Habtamu K, Alem A, Medhin G, Fekadu A, Dewey M, et al. (2017) Validation of the World Health Organization Disability Assessment Schedule in people with severe mental disorders in rural Ethiopia. Health Qual Life Outcomes 15(1): 1-11.

22. Sveinsdottir V, Tveito TH, Bond GR, Grasdal AL, Lie SA, et al. (2016) Protocol for the SEED-trial: Supported Employment and preventing Early Disability. BMC Public Health 16(1): 1-8.

23. Corbière M, Zaniboni S, Dewa C, Villotti P, Lecomte T, et al. (2019) Work productivity of people with a psychiatric disability working in social firms. Work 62(1): 151-160.

24. Danielsson L, Elf M, Hensing G (2019) Strategies to keep working among workers with common mental disorders - a grounded theory study. Disabil Rehabil 41(7): 786-795.

$\begin{array}{ll}\text { BIOMEDICAL } & \text { Assets of Publishing with us } \\ \text { RESEARCHES } & \text { - Global archiving of articles } \\ & \text { - Immediate, unrestricted online access } \\ & \text { - Rigorous Peer Review Process } \\ & \text { - Anttps://biomedres.us/ }\end{array}$

